\title{
Um Estudo sobre as Evidenciações Contábeis do Governo do Estado de Pernambuco sob a Ótica da Teoria da Legitimidade e dos Custos Políticos
}

\section{A Study on the Financial disclosures of the State of Pernambuco in the Optics Theory of Legitimacy and Political Costs}

\section{Un Estudio sobre las Revelaciones Financieras del Estado de Pernambuco en la Óptica Teoría de la Legitimidad y Costos Políticos}

\author{
João Nascimento de Araújo \\ Mestrando em Ciências Contábeis UFPE \\ Universidade Federal de Pernambuco, Centro de \\ Ciências Sociais Aplicadas. \\ Av. dos Reitores s/n, Cidade Universitária, CEP: \\ 50.670-901, Recife, PE, Brasil, Telefone: (81) 2126-8874 \\ e-mail: j_gabrie190@hotmail.com \\ Av. dos Reitores s/n, Cidade Universitária, CEP: \\ 50.670-901, Recife, PE, Brasil, Telefone: (81) 2126-8874, \\ e-mail: umbelinalagioia@gmail.com
}

Tiago de Moura Soeiro

Mestrando em Ciências Contábeis UFPE

Universidade Federal de Pernambuco, Centro de

Ciências Sociais Aplicadas.

Av. dos Reitores s/n, Cidade Universitária, CEP:

50.670-901, Recife, PE, Brasil, Telefone: (81) 2126-8874, e-mail: tiago-soeiro@hotmail.com

Francisco de Assis Carlos Filho, Me.

Universidade Federal de Pernambuco, Centro de Ciências Sociais Aplicadas.

Av. dos Reitores s/n, Cidade Universitária, CEP: 50.670-901, Recife, PE, Brasil, Telefone: (81) 2126-8874, e-mail: francisco.assis@upe.br

\section{RESUMO}

Este trabalho teve como objetivo investigar, sob a ótica da Teoria da Legitimidade e dos Custos Políticos, como estão sendo apresentadas as evidenciações contábeis compulsórias e voluntárias que o Governo do Estado de Pernambuco disponibiliza em seu sítio eletrônico. Para tal, baseado em método indutivo, foi realizada uma pesquisa qualitativa, exploratória e com análise documental. Para a análise dos resultados utilizou-se metodologia semelhante as de Beuren e Söthe (2009) e Avelino, Colauto e Cunha (2010). Foram analisados o cumprimento das Lei no 9.755/1998 e a Lei Complementar no 101/2000, quanto as divulgações das evidenciações compulsórias; com base nos parâmetros apresentados por Hendriksen e Van Breda (1999) de níveis de evidenciação; bem como as características qualitativas de informação do Pronunciamento Conceitual Básico (R1) do CPC (2011). Assim, o resultado a pesquisa aponta que as evidenciações compulsórias e voluntárias apresentadas pelo Estado de Pernambuco, não atingem completamente sua legitimidade perante a sociedade, pois as evidenciações não atendem de forma total os níveis de evidenciação justa e completa, bem como as características qualitativas de compreensibilidade e fidedignidade. Infere-se desses achados, portanto, que o Estado de Pernambuco não se sente potencialmente ameaçado em sua legitimidade perante a sociedade, considerando, desta forma, o custo político do aumento dos níveis e qualidade das evidenciações frente à perda da legitimidade.

Palavras-chave: Teoria da Legitimidade; Custos Políticos; Evidenciações Contábeis.

\footnotetext{
${ }^{1}$ Artigo recebido em 08.08.2014. Aceito para publicação em 01.12.2014. Recomendado para publicação por José Ribamar Marques de Carvalho (Editor Científico). Publicado em 30.12.2014. Organização responsável CCJS/UFCG.
} 


\begin{abstract}
This study aimed to investigate, from the perspective of Legitimacy Theory and Political Costs, are presented as compulsory and voluntary accounting disclosures that the State Government of Pernambuco available on its website. To this end, based on inductive method, a qualitative, exploratory and documentary analysis was undertaken. For the analysis of the results we used the same methodology de Beuren and Sothe (2009) and Avelino, Colauto and Cunha (2010). Compliance with the Law No. 9755/1998 and Complementary Law No. 101/2000, as the disclosures of compulsory disclosures were analyzed; based on the parameters presented by Hendriksen and Van Breda (1999) levels of disclosure; well as the qualitative characteristics of information Pronouncement conceptual Basic (R1) of the CPC (2011). Thus, the research result indicates that compulsory and voluntary disclosures submitted by the State of Pernambuco, not quite reach its legitimacy in society, because the disclosures do not meet the full picture of the levels of fair and complete disclosure, as well as the qualitative characteristics of responsiveness and reliability. These findings it is inferred, therefore, that the State of Pernambuco not feel potentially threatened in its legitimacy in society, considering thus the political cost of increased levels and quality of disclosures against the loss of legitimacy.
\end{abstract}

Keywords: Legitimacy Theory; Political Costs; Accounting disclosure.

RESUMEN

Este estudio tuvo como objetivo investigar, desde la perspectiva de la teoría de la legitimidad y los costos políticos, como revelaciones contables obligatorios y voluntarios que el Gobierno del Estado de Pernambuco ofrece a través del sitio web se presentan. Con este fin, basado en el método inductivo, un estudio cualitativo se llevó a cabo un análisis exploratorio y documento. Para analizar los resultados se utilizó la misma metodología de Beuren y sothe (2009) y Avelino, Colauto y Cunha (2010). Se analizó el cumplimiento de la Ley N॰9.755 / 1998 y la Ley Complementaria № 101/2000, ya que las revelaciones de las revelaciones obligatorias; sobre la base de los parámetros presentados por Hendriksen y Van Breda (1999) de los niveles de divulgación; así como las características cualitativas de la información del Concepto Norma básica (R1) del Código (2011). Por lo tanto, el resultado de la investigación muestra que las revelaciones obligatorias y voluntarias presentadas por el Estado de Pernambuco, alcanzan no completamente su legitimidad en la sociedad, debido a que las revelaciones no cumplen con los niveles de forma general de divulgación justa y completa, así como las características cualitativas de capacidad de respuesta y fiabilidad. Se desprende de estos resultados, por lo tanto, que el Estado de Pernambuco no se siente amenazado potencialmente sobre su legitimidad en la sociedad, teniendo en cuenta de esta manera, el costo politico de aumentar los niveles y la calidad de las revelaciones en comparación con la pérdida de legitimidad.

Palabras clave: Teoría de la legitimidad; Los costos políticos; Revelaciones

\title{
1 INTRODUÇÃO
}

A divulgação da informação contábil, conforme CPC (2011), deve ser capaz de evidenciar os eventos de caráter patrimonial, econômico e financeiro, de forma que atenda as necessidades comuns dos seus usuários, sejam eles internos ou externos.

De acordo com Dantas, Zendersky e Niyama (2004), evidenciação não implica somente em divulgar, mas divulgar com qualidade, oportunidade e clareza. Destacam também que, para alcançar a transparência pretendida com a evidenciação, a instituição deve divulgar informações qualitativas e quantitativas que possibilitem aos usuários formar uma compreensão das atividades desenvolvidas e dos seus riscos.

Nesse contexto, aplica-se a Teoria da Legitimidade a Contabilidade pois, conforme Dias Filho (2009), tal aplicação se baseia na concepção de que existe um contrato social entre a entidade e a sociedade onde uma das formas de demonstrar o cumprimento de tal contrato é através das Demonstrações Contábeis.

As entidades, principalmente aquelas que atuam em setores sensíveis a questões políticas, incorrem muitas vezes em Custos Políticos, definidos por Watts e Zimmerman (1978), como aqueles decorrentes de questões contratuais, de lobbies e/ou provenientes de algum tipo de regulação. Dessa forma, segundo Beuren e Söthe (2009) quando a entidade não realiza as suas atividades em conformidade com o que 
a sociedade espera, em especial aquelas mais sensíveis a questões políticas, como é o caso do setor público, torna-se necessária a ampliação dos níveis de evidenciação, acarretando no aumento dos custos políticos. Assim, por meio da inclusão de informações sociais nos relatórios anuais, os gestores procuram evitar a intervenção política.

A busca das entidades pela legitimidade e pela redução dos custos políticos tem sido discutida em vários estudos ao longo dos últimos anos. Dentre os quais se destacam os trabalhos de Patten e Trompeter (2003), Frey e Frey (2004), Silva e Sancovschi (2006) e Bispo et al. (2007) que avaliam a temática no âmbito do setor privado. No setor público, são relevantes os trabalhos de Platt Neto, Cruz e Vieira (2007), que analisam a teoria da legitimidade e a hipótese de custos políticos em universidades brasileiras e Beuren e Söthe (2009) e Avelino, Colauto e Cunha (2010) que abordam a temática em questão, respectivamente, quanto aos governos estados do Sudeste e as principais cidades do Estado de Minas Gerais, buscando verificar se tais governos buscavam se legitimar através de suas evidenciações compulsórias e voluntárias, bem como se consideravam a questão dos custos políticos atrelados a tais evidenciações.

Em seus estudos, Patten e Trompeter (2003) analisaram a relação entre os níveis de evidenciação ambiental e o gerenciamento de lucros no contexto da resposta da indústria química a um acidente ocorrido em 1984. Frey e Frey (2004) e Silva e Sancovschi (2006) investigaram a forma como empresas brasileiras com alto custo político, respectivamente a Souza Cruz S.A. e a Petróleo Brasileiro S.A., utilizaram a evidenciação voluntária de informações sociais em seus relatórios anuais, no período de 1993 a 2002, para encaminhar questões negativas relacionadas com seus produtos, frente a uma possível ameaça ou perda de legitimidade. Outro estudo, realizado por Bispo et al. (2007), discute a relação entre carga tributária, os setores econômicos, os tamanhos das empresas brasileiras e o custo político do enquadramento da empresa nestes ambientes.

No âmbito da transparência pública Platt Neto, Cruz e Vieira (2006) realizaram um estudo com o objetivo de caracterizar e apresentar considerações sobre o uso da Internet como instrumento de publicidade aliado à transparência das contas públicas das universidades brasileiras, buscando estudar as evidenciações contábeis compulsórias e voluntárias de entidades públicas estaduais e o custo político da manutenção da legitimidade. Beuren e Söthe (2009) investigaram a evidenciação de informações contábeis que os governos estaduais da região sudeste do Brasil disponibilizavam aos usuários dessas informações. Já Avelino, Colauto e Cunha (2010) investigaram a evidenciação no governo do estado de Minas Gerais e nos maiores municípios Mineiros. Tanto o estudo de Beuren e Söthe (2009) quanto o de Avelino, Colauto e Cunha (2010) apontaram resultados que indicavam a não preocupação dos governos analisados em se legitimar perante a sociedade, bem como com a hipótese de custos políticos atrelada a divulgação das informações contábeis. 
De tal forma, a pesquisa se apoia na relação entre os entes públicos e a sociedade, e a necessidade que esses entes têm de prestar conta de seus atos e a população, cada vez mais, tem de fiscalizar e tomar conhecimento sobre as atividades dos administradores públicos.

Diante do exposto esta pesquisa busca investigar, sob a ótica da Teoria da Legitimidade e dos Custos Políticos: Como estão sendo apresentadas as evidenciações contábeis compulsórias e voluntárias que o Governo do Estado de Pernambuco disponibiliza em seu sítio eletrônico?

\section{REFERENCIAL TEÓRICO}

O referencial teórico está dividido em três tópicos, o primeiro versará sobre a teoria da legitimidade e a hipóteses dos custos políticos. Depois, serão apresentadas as considerações sobre evidenciação voluntária e compulsória nas entidades públicas, por fim, para um melhor entendimento sobre o conteúdo dessa pesquisa, serão apresentadas as características qualitativas nas evidenciações contábeis.

\subsection{Teoria da Legitimidade e Hipótese dos Custos Políticos}

Sob a perspectiva da existência de um contrato entre as organizações e a sociedade, considera-se que as entidades estão sempre procurando desenvolver suas atividades de acordo com os parâmetros sociais, de modo a estabelecer congruência entre suas atividades e as expectativas da sociedade. Assim, se legitimam na medida em que alinham suas práticas com normas e padrões comportamentais defendidos no ambiente em que atuam. (DIAS FILHO, 2009; O'DONOVAN 2002). Tais contratos fornecem uma visão geral do conceito de contrato social pelo qual as instituições operam na sociedade. Pode ser expresso ou implícito, pelo que a sua sobrevivência e crescimento são baseados em: (i) a entrega de alguns fins socialmente desejáveis para a sociedade em geral; e (ii) a distribuição de benefícios econômicos, sociais ou políticos de grupos da qual deriva seu poder. (SHOCKER; SETHI, 1973)

Boff (2007) afirma que uma entidade quando passa a fazer parte de um novo ambiente tem a opção de aceitar e adequar-se aos padrões já definidos e legitimados, diminuindo o risco de sua não aceitação pelas demais organizações e indivíduos, ou então, estabelece seus próprios padrões. Ao tomar essa postura, a entidade manifesta-se de maneira indiferente aos padrões e regras já estabelecidos no ambiente, porém, ela poderia colocar em risco sua legitimidade, visto que apresenta discrepância de comportamento em relação ao ambiente em que atua.

Zimmerman \& Zeitz (2002), entendem que a legitimidade é concedida a uma organização por interessados externos que endossam a dignidade da visão ou objetivos da organização e sua competência para funcionar de forma eficiente para alcançar os objetivos designados. Segundo Marens e Wicks (1999), a legitimidade 
pode ser discutida em cada nível de uma população, tratando-se de um conceito amplo, pode abranger a avaliação geral de uma empresa e de suas atividades por seus stakeholders.

Para Neu, Warsame e Pedwell (1998), empresas bem legitimadas no ambiente em que operam conseguem superar obstáculos mais facilmente, evitando os custos decorrentes e garantindo maior regularidade e conseguindo maior apoio. Assim, Dias Filho (2009) coloca que é uma estratégia da empresa o esforço para se legitimar, de forma que continuem operando ao menor custo possível os recursos necessários e cumprindo seus objetivos.

Como estratégias de legitimação, a organização pode adaptar sua produção, objetivos e métodos de funcionamento em conformidade com as definições vigentes de legitimidade, bem como, através da comunicação, alterar a definição de legitimidade do meio em que atua para que esteja em conformidade com as práticas atuais da organização, produção e valores; pode tentar por meio da comunicação se identificar com símbolos, valores ou instituições que têm uma forte base de legitimidade. (DOWLING; PFEFFER, 1975).

Além disso, a entidade pode procurar: educar e informar os seus "públicos relevantes" sobre reais mudanças no desempenho da organização e atividades; mudar as percepções dos públicos relevantes, mas não mudar seu comportamento real; manipular a percepção, desviando a atenção da questão de preocupação para outros assuntos relacionados através de um apelo para, por exemplo, os símbolos emotivos; ou procurar mudar as expectativas externas de seu desempenho. (GRAY; KOUHY; LAVERS, 1995).

A hipótese de custos políticos, de Watts e Zimmerman (1978), presume que grandes empresas inseridas em setores sensíveis a questões políticas tais como, a indústria farmacêutica, o setor de serviços públicos, o setor florestal e a indústria de petróleo e gás, estão sujeitas a custos políticos, aqueles decorrentes de relações contratuais, de lobbies e/ou de regulação, potencialmente elevados. Assim, essas empresas se sentem motivadas a reduzir sua exposição pública, utilizando como meios para atingir tal exposição os modos e a quantidade de divulgação de suas informações.

Dessa forma Beuren e Söthe (2009) colocam que organizações, especialmente aquelas com custos políticos potencialmente elevados, quando se sentem ameaçadas, necessitam e procuram ampliar as evidenciações compulsórias e voluntárias, recuperando ou diminuindo a possibilidade de perda da legitimidade.

Portanto, de acordo com Silva e Sancovschi (2006), a teoria da legitimidade e a hipótese do custo político auxiliam na explicação do aumento da evidenciação social, principalmente quando existe um ambiente de pressão pública nos campos social e ambiental. Sob esta perspectiva afirmam Beuren e Söthe (2009) que, de idêntica forma, os entes públicos estão sendo constantemente fiscalizados pela sociedade e, consequentemente, precisam estar atentos tanto nos custos políticos quanto na legitimidade de seus atos. 


\subsection{Evidenciação Compulsória e Voluntária em Entidades Públicas}

Nas entidades públicas a evidenciação compulsória é estabelecida inicialmente pela Lei 4.320/1964 nos art. 2 ${ }^{\circ}$ e 89, que institui normas gerais de Direito Financeiro para a elaboração e controle dos orçamentos e balanços da União, dos Estados, dos Municípios e do Distrito Federal.

A primeira iniciativa legal no sentido de incorporar a obrigatoriedade da divulgação de informações das contas públicas na Internet surgiu com a Lei 9.755/1998, que menciona a necessidade da criação de homepage pelo Tribunal de Contas da União, com o título "contas publicas" (www.contaspublicas.gov.br), para a divulgação das evidenciações compulsórias de natureza orçamentária e financeira (AVELINO; COLAUTO E CUNHA, 2010).

Afirmam Avelino, Colauto e Cunha (2010) que a "divulgação de informações na Internet, portanto, é uma opção de política de gestão que garante a transparência dos atos dos entes públicos, o que transcende a simples obrigação legal". Nesse contexto, Goulart (2003) coloca que as entidades não devem restringir a sua divulgação às informações requeridas em lei. Ao contrário, devem divulgar outras informações que colaborem para que o público constitua uma visão correta sobre a realidade empresarial.

Posteriormente, a publicação da Lei Complementar 101/2000 (Lei de Responsabilidade Fiscal - LRF) contribuiu significativamente para aumentar a exigência de transparência no âmbito das entidades públicas ao determinar o que são instrumentos de transparência da gestão fiscal, aos quais será dada ampla divulgação, inclusive em meios eletrônicos de acesso público, conforme seu Art. 48: os planos, orçamentos e leis de diretrizes orçamentárias; as prestações de contas; o Relatório Resumido da Execução Orçamentária e o Relatório de Gestão Fiscal.

Ainda no esforço para conferir maior transparência à gestão pública, a Lei Complementar 131/2009 acrescentou dispositivos à Lei 101/2000. Uma modificação importante foi o acréscimo da sanção para o ente federativo que não disponibilizar as informações. Tal sanção está prevista no Art. 23 da LRF, em seu parágrafo 3ㅜ, inciso I, e impede o ente de receber transferências voluntárias, enquanto não atender os prazos para divulgação das informações (AVELINO; COLAUTO E CUNHA, 2010).

No tocante ao nível de evidenciação, Hendriksen e Van Breda (1999, p. 515) descrevem que "o nível de divulgação também depende do padrão considerado mais desejável. Três conceitos de divulgação são geralmente propostos: divulgação adequada, justa e completa".

Para esse estudo as três formas de divulgação são consideradas aplicáveis, uma vez que, a legislação determina a apresentação mínima das informações contábeis (nível de evidenciação adequada). Tais divulgações, tanto voluntárias quanto obrigatórias, devem apresentadas de forma padronizada para tratar igualmente todos os usuários da informação (nível de evidenciação justa). Não obstante, a legislação não inibe a divulgação de informações adicionais que os 
gestores públicos julgarem relevantes (nível de evidenciação completa). O quadro a seguir sintetiza os conceitos e suas definições.

Quadro 1 - Níveis de evidenciação

\begin{tabular}{|l|l|}
\hline \multicolumn{1}{|c|}{ Nível } & \multicolumn{1}{c|}{ Definição } \\
\hline Adequada & $\begin{array}{l}\text { Divulgação em volume mínimo para as demonstrações não } \\
\text { serem enganadoras }\end{array}$ \\
\hline Justa & Trata igualmente seus leitores em potencial \\
\hline Completa & Apresenta todo tipo de informação relevante \\
\hline
\end{tabular}

Fonte: Elaboração própria com base em Hendriksen e Van Breda (1999).

É relevante, portanto, conforme salientam Beuren e Söthe (2009), que o gestor público avalie as informações a serem divulgadas, tanto as quantitativas, quanto as qualitativas, especialmente pelo caráter social que estas apresentam, além de receberem níveis diferenciados de avaliação.

\subsection{Características Qualitativas das Evidenciações Contábeis}

O Comitê de Pronunciamentos Contábeis (CPC) criado por meio da Resolução do Conselho Federal de Contabilidade (CFC) no 1.055/05, com o objetivo de emissão de pronunciamentos contábeis para a convergência da contabilidade brasileira aos padrões internacionais, em seu Pronunciamento Conceitual Básico (R1), oficializado pela Deliberação da Comissão de Valores Mobiliários (CVM) nº 875/2011 e pela Resolução do CFC no 1.374/2011, dispõe sobre a estrutura conceitual para a elaboração e apresentação das demonstrações contábeis, aplicável às entidades públicas e privadas, estabelecendo que as demonstrações contábeis devam atender as necessidades dos seus usuários.

Por meio deste Pronunciamento, o CPC (2011) apresenta as características qualitativas das Demonstrações Contábeis. Segundo Iudícibus et al. (2010, p 37) essas características são "atributos que tornam as demonstrações uteis para os usuários".

Tais características são separadas em fundamentais e de melhoria. As fundamentais são Relevância e Fidedignidade, enquanto que as de melhoria são Comparabilidade, Verificabilidade, Tempestividade e Compreensibilidade. No Quadro abaixo são apresentados os principais conceitos das características.

Quadro 2 - Características Qualitativas das Demonstrações Contábeis

\begin{tabular}{|l|l|}
\hline \multicolumn{1}{|c|}{$\begin{array}{c}\text { Características } \\
\text { Qualitativas }\end{array}$} & \multicolumn{1}{c|}{ Conceitos } \\
\hline Relevância & $\begin{array}{l}\text { É aquela capaz de fazer diferença nas decisões que possam ser tomadas } \\
\text { pelos usuários. }\end{array}$ \\
$\begin{array}{l}\text { A materialidade é um aspecto de relevância específico da entidade baseado } \\
\text { na natureza ou na magnitude, ou em ambos, dos itens para os quais a } \\
\text { informação está relacionada no contexto do relatório contábil-financeiro de } \\
\text { uma entidade em particular. }\end{array}$ \\
\hline
\end{tabular}




\begin{tabular}{|l|l|}
\hline Fidedignidade & $\begin{array}{l}\text { Para ser representação perfeitamente fidedigna, a realidade retratada } \\
\text { precisa ter três atributos. Ela tem que ser completa, neutra e livre de erro. O } \\
\text { objetivo é maximizar referidos atributos na extensão que seja possível. }\end{array}$ \\
\hline Comparabilidade & $\begin{array}{l}\text { A informação acerca da entidade que reporta informação será mais útil } \\
\text { caso possa ser comparada com informação similar sobre outras entidades e } \\
\text { com informação similar sobre a mesma entidade para outro período ou } \\
\text { para outra data. }\end{array}$ \\
\hline Verificabilidade & $\begin{array}{l}\text { Significa que diferentes observadores, cônscios e independentes, podem } \\
\text { chegar a um consenso, embora não cheguem necessariamente a um } \\
\text { completo acordo, quanto ao retrato de uma realidade econômica em } \\
\text { particular ser uma representação fidedigna. }\end{array}$ \\
\hline Tempestividade & $\begin{array}{l}\text { Significa ter informação disponível para tomadores de decisão a tempo de } \\
\text { poder influenciá-los em suas decisões. }\end{array}$ \\
\hline Compreensibilidade & $\begin{array}{l}\text { Classificar, caracterizar e apresentar a informação com clareza e concisão } \\
\text { torna-a compreensível. }\end{array}$ \\
\hline
\end{tabular}

Fonte: Elaboração própria com base no CPC (2011).

Nesse sentido, afirma Iudícibus et al. (2010) que é preciso que haja, na prática, um equilíbrio entre essas características, com finalidade de satisfazer os objetivos das Demonstrações Contábeis. Cabendo, portanto, um julgamento profissional que difere em cada caso específico.

Outro ponto a ser observado, conforme o CPC (2011) é a relação entre os custos e os benefícios da evidenciação. Nesse sentido, diferenças podem ocorrer em decorrência do tamanho das entidades, das necessidades de seus usuários ou de outros fatores.

\section{PROCEDIMENTOS METODOLÓGICOS}

A pesquisa foi efetuada através de método indutivo uma vez que, como afirma Silva (2003), parte-se de registros menos gerais para enunciados mais gerais, fundamentado e amparado em análise de conteúdo e documental, pois foram utilizadas fontes oriundas de materiais concretamente já elaborados.

Quanto aos seus objetivos, é de caráter exploratório, no que tange ao procedimento, foi realizada por meio de pesquisa documental e, em relação à abordagem do problema, o estudo é de caráter qualitativo (RAUPP e BEUREN, 2004)

Desta forma a seguinte pesquisa: (i) Coletou os dados no sítio eletrônico do Governo do Estado de Pernambuco; (ii) Avaliou o nível de evidenciação de informação compulsória estabelecida pela legislação, mais especificamente o que determinam a Lei no 9.755/1998 e a Lei Complementar n⿳ํㅜ101/2000, e também o nível de evidenciação voluntária, tomando como critério a classificação de Hendriksen e Van Breda (1999) de adequada, justa e completa, com as devidas limitações de análise apresentadas no referencial teórico; (iii) Categorizou os atributos das evidenciações compulsória e voluntária, tomando como critério as características qualitativas da informação, contidas no Pronunciamento Conceitual Básico (R1) - 
Estrutura Conceitual para Elaboração e Divulgação de Relatório Contábil-Financeiro; (iv) Verificou, através de análise documental, a Legitimidade e os Custos Políticos do Governo do Estado de Pernambuco com base nas avaliações propostas. Desta forma, optou-se por escolher o modelo de análise idêntico ao dos artigos de Beuren e Söthe (2009) e Avelino, Colauto e Cunha (2010), por tratar das características qualitativas utilizadas na CPC 00, uma vez que na NBCT SP 16.5 - Registro Contábil existem características da informação de difícil constatação para a metodologia da coleta dos dados empregada. Além disto, a escolha deste modo permite comparar os achados desta obra com os das obras citadas.

O estudo se limitará a identificar os níveis e qualidade das evidenciações contábeis do Estado de Pernambuco, não se preocupando em identificar e comprovar os eventos que limitam a apresentação das evidenciações.

\section{APRESENTAÇÃO E DISCUSSÃO DOS RESULTADOS}

Esse capítulo está estruturado em quatro tópicos, o primeiro de introdução será a apresentação da estrutura de onde os dados foram retirados, o segundo dele será a análise sobre evidenciação compulsória e o terceiro sobre evidenciação voluntária. Por fim, no quarto tópico será feita análise dessas evidenciações.

\subsection{Estrutura do Sítio Pesquisado}

Inicialmente, foi pesquisado na rede o sítio eletrônico do governo do Estado de Pernambuco (http://www.pe.gov.br/). Foi feita uma pesquisa na página buscando as informações contábeis, onde, apesar de não possuir link direto na página inicial, é de fácil acesso encontrar o espaço próprio para tais divulgações, denominado de "Portal da Transparência".

\subsection{Evidenciações Compulsórias}

Na segunda fase da pesquisa foram analisadas as evidenciações compulsórias de acordo com a disposição da Lei no 9.755/1998 e da Lei Complementar no 101/2000 (Lei de Responsabilidade Fiscal - LRF). Constatou-se que o Estado analisado possui cadastro na página eletrônica do Tribunal de Contas da União (http://www.contaspublicas.gov.br). No entanto, não disponibilizou nenhum link de acesso das contas públicas na página eletrônica deste órgão que permita o acesso às evidenciações contábeis compulsórias.

Por meio do acesso às informações disponíveis na página eletrônica do próprio governo, realizou-se a análise, conforme demonstrado no quadro a seguir. 
Quadro 3 - Evidenciações contábeis compulsórias do Estado de Pernambuco

\begin{tabular}{|c|c|}
\hline Evidenciações Compulsórias & PE \\
\hline a) Arrecadações (Lei no 9.755/1998) & Sim \\
\hline $\begin{array}{l}\text { b) Relatório Resumido de Execução Orçamentária (Lei no } \\
\text { 9.755/1998 e LRF - LC no } 101 / 2000 \text { ) }\end{array}$ & Sim \\
\hline c) Balanços (Lei no 9.755/1998) & Sim \\
\hline d) Contratos, aditivos e suas ratificações (Lei no 9.755/1998) & Sim \\
\hline e) Relações das compras (Lei nº 9.755/1998) & Sim \\
\hline f) Plano Plurianual (LRF - LC no 101/2000) & Sim \\
\hline g) Orçamento Anual (LRF - LC no 101/2000 e Lei no 9.755/1998) & Sim \\
\hline h) Lei de Diretrizes Anual (LRF - LC no 101/2000) & Sim \\
\hline i) Prestação de Contas e Parecer Prévio (LRF - LC nº 101/2000) & Sim \\
\hline j) Relatório de Gestão Fiscal (LRF - LC nº 101/2000) & Sim \\
\hline
\end{tabular}

Fonte: Dados da pesquisa, (2013)

Constatou-se que o governo do Estado de Pernambuco publicou integralmente o que dispõe a Lei $n^{\circ}$ 9.755/1998, bem como a Lei Complementar no 101/2000. Este resultado difere das pesquisas de Beuren e Söthe (2009) e de Avelino, Colauto e Cunha (2010) que, nos resultados de seus trabalhos, observaram que nem mesmo as informações previstas legalmente estavam dispostas nos sítios eletrônicos dos governos por eles analisados.

\subsection{Evidenciações Voluntárias}

A terceira fase da análise refere-se à identificação dos tipos de informações voluntárias evidenciadas em cada um dos sítios, conforme demonstrado no quadro a seguir:

\begin{tabular}{|c|c|}
\hline & Evidenciações voluntárias \\
\hline \multirow{11}{*}{ PE } & $\begin{array}{l}\text { a) Evidenciação das Receitas: total do estado; por poder; por } \\
\text { orgão; por U.G. }\end{array}$ \\
\hline & $\begin{array}{l}\text { b) Evidenciação das despesas: total do estado; por poder; por } \\
\text { orgão; por U.G. }\end{array}$ \\
\hline & c) Detalhamento das Despesas: por credor e por empenho \\
\hline & d) Evidenciação dos Convênios \\
\hline & $\begin{array}{l}\text { e) Direcionamento para evidenciação da Remuneração dos } \\
\text { servidores }\end{array}$ \\
\hline & f) Gráfico de comportamento das Receitas \\
\hline & g) Gráfico de comportamento das Despesas \\
\hline & h) Demonstrativo de ações por região \\
\hline & i) Precatórios \\
\hline & j) Informações sobre os repasses aos municípios \\
\hline & k) Evidenciação dos programas e Recursos da Educação \\
\hline
\end{tabular}

Fonte: Dados da pesquisa, (2013). 
O Governo do Estado de Pernambuco apresentou um conjunto significativo de evidenciações, além de boa quantidade de demonstrativos, destacando-se o detalhamento de receitas e despesas, convênios e o demonstrativo de ações por região, assim como dados específicos relativos à educação. Entretanto, boa parte das informações é sintética, sendo poucas aquelas de caráter mais analítico.

De acordo com a Teoria da Legitimidade, conforme apontado por Beuren e Söthe (2009, p. 112):

As entidades necessitam demonstrar constantemente à sociedade a sua importância e legitimar os seus atos, isto é, precisam evidenciar o cumprimento do contrato social existente entre o governo e a sociedade. Com custos políticos potencialmente elevados, os governos precisam estar atentos para não ter ameaçada a sua legitimidade. Ampliar evidenciações compulsórias e voluntárias pode contribuir no sentido de manter ou diminuir a possibilidade de perda da legitimidade.

\subsection{Análise dos Níveis das Evidênciações Compulsórias e Voluntárias}

Para análise dos níveis de evidenciação contábil, utilizou-se as categorias apresentadas por Hendriksen e Van Breda (1999), divulgação Adequada, Justa e Completa, conforme apresentado no Quadro 1. Os parâmetros para o enquadramento dos níveis de evidenciação compulsória e voluntária nessas três categorias foram os itens de evidenciação apontados nos Quadros 3 e 4. Desta forma, os quadros a seguir apresentam os níveis de evidenciação compulsória e voluntária do Estado analisado.

Quadro 5 - Níveis de evidenciação da informação contábil

\begin{tabular}{|c|c|c|c|c|c|c|}
\hline \multirow{2}{*}{$\begin{array}{c}\text { Estado } \\
\text { PE }\end{array}$} & \multicolumn{3}{|c|}{ Evidenciação Compulsória } & \multicolumn{3}{|c|}{ Evidenciação Voluntária } \\
\hline & Satisfaz & $\begin{array}{c}\text { Satisfaz } \\
\text { Parcialmente }\end{array}$ & \begin{tabular}{|c|} 
Não \\
Satisfaz
\end{tabular} & Satisfaz & $\begin{array}{c}\text { Satisfaz } \\
\text { Parcialmente }\end{array}$ & $\begin{array}{l}\text { Não } \\
\text { Satisfaz }\end{array}$ \\
\hline Adequada & $\begin{array}{l}a, b, c \\
d, e, f, \\
g, h, i, j\end{array}$ & & & $\begin{array}{l}\text { Não se } \\
\text { aplica }\end{array}$ & & \\
\hline Justa & & $\begin{array}{l}a, b, c, d, e, f, \\
g, h, i, j\end{array}$ & & $\begin{array}{l}a, b, c, d, \\
e, f, g, h, \\
i, j, k\end{array}$ & & \\
\hline Completa & $\begin{array}{l}\text { Não se } \\
\text { aplica }\end{array}$ & & & & $\begin{array}{l}a, b, c, d, e, f, \\
g, h, i, j, k\end{array}$ & \\
\hline
\end{tabular}

Fonte: Dados da pesquisa, (2013).

A divulgação adequada, compreendida como aquela considerada a mínima necessária para que as informações possam ser compreendidas por parte de seus usuários, foi identificada no Estado analisado, considerando-se que estavam apresentadas todas as evidenciações compulsórias. Este critério não foi aplicado às 
evidenciações voluntárias, uma vez que, pela sua natureza não obrigatória, extrapolam o limite de divulgação mínima.

Quanto à análise do nível de evidenciação justa, foi possível identificar que, as informações são disponibilizadas todas as demonstrações a todos os usuários ao mesmo tempo. No entanto, a compreensibilidade destas informações se mostra prejudicada nas das evidenciações compulsórias como um todo. Contudo, as evidenciações voluntárias em geral podem ser compreendidas com maior facilidade pelos usuários.

$\mathrm{Na}$ análise quanto às informações completas das evidenciações apresentadas, constatou-se que as evidenciações voluntárias são limitadas, pois, assim como achado por Beuren e Söethe (2009) a informação completa é constituída de um grande número de demonstrações sintéticas e analíticas, enquanto que as voluntárias, em sua grande maioria, apresentam apenas informações sintéticas. Esse nível de evidenciação não se aplica as evidenciações compulsórias, uma vez que elas já compõem o limite mínimo de informação a ser evidenciada.

\subsection{ANÁLISE DAS CARACTERÍSTICAS QUALITATIVAS DAS EVIDÊNCIAÇÕES}

Como parâmetros para a análise das características qualitativas das evidenciações, foram utilizadas as definições apresentadas no Quadro 2, referentes à Relevância, Fidedignidade, Comparabilidade, Tempestividade e Compreensibilidade. Nos quadro 6 estão expostos os resultados das características qualitativas das demonstrações contábeis analisadas.

Quadro 6 - Características qualitativas das informações contábeis.

\begin{tabular}{|c|c|c|c|c|c|c|}
\hline \multirow{2}{*}{$\begin{array}{c}\text { Estado } \\
\text { PE } \\
\end{array}$} & \multicolumn{3}{|c|}{ Evidenciação Compulsória } & \multicolumn{3}{|c|}{ Evidenciação Voluntária } \\
\hline & Total & Parcial & Nula & Total & Parcial & Nula \\
\hline Relevância & $\begin{array}{l}a, b, c, d, \\
e, f, g, h, \\
i, j\end{array}$ & & & $\begin{array}{l}a, b, c, d, \\
e, f, g, h, \\
i, j, k\end{array}$ & & \\
\hline Fidedignidade & $\begin{array}{l}a, b, c, d, \\
e, f, g, h, \\
i, j\end{array}$ & & & & $\begin{array}{l}a, b, c, d, \\
e, f, g, h, \\
i, j, k\end{array}$ & \\
\hline Comparabilidade & $\begin{array}{l}a, b, c, d, \\
e, f, g, h, \\
i, j\end{array}$ & & & $\begin{array}{l}a, b, c, d, \\
e, f, g, h, \\
i, j, k\end{array}$ & & \\
\hline Tempestividade & $\begin{array}{l}a, b, c, d, \\
e, f, g, h, \\
i, j\end{array}$ & & & $\begin{array}{l}a, b, c, d, \\
e, f, g, h, \\
i, j, k\end{array}$ & & \\
\hline Compreensibilidade & & $\begin{array}{l}a, b, c, d, \\
e, f, g, h, \\
i, j\end{array}$ & & $\begin{array}{l}a, b, c, d, \\
e, f, g, h, \\
i, j, k\end{array}$ & & \\
\hline
\end{tabular}


Fonte: Dados da pesquisa, (2013).

Todas as informações disponibilizadas são enquadradas como relevantes, uma fez que são capazes de fazer a diferença nas decisões que possam vir a serem tomadas. Contudo, a complexidade das divulgações compulsórias pode se tornar um entrave para interpretações adequadas acerca do que está divulgado. Por outro lado, as informações voluntárias, embora também relevantes, tem como limitação a pouca quantidade de informações mais detalhadas.

$\mathrm{Na}$ análise da fidedignidade das evidenciações compulsórias destaca-se a presença dos pareceres do tribunal de contas do estado. Quanto as evidenciações voluntárias, não apresentaram quaisquer comprovações acerca do seu conteúdo.

No tocante à característica da comparabilidade, as evidenciações compulsórias apresentadas pelos entes públicos permitem que o usuário analise a gestão comparando-se os valores orçados e realizados no exercício financeiro, bem como se notou a publicação simultânea das informações de dois ou mais exercícios subsequentes em boa parte dos relatórios. Analisando-se as evidenciações voluntárias, nota-se que as informações disponibilizadas pelo Estado de Pernambuco permitem a comparação da evolução de alguns índices, contando ainda com o auxílio de gráficos como forma de auxiliar as comparações.

No que tange à tempestividade, o sítio eletrônico disponibiliza tanto as informações compulsórias quanto as voluntárias em tempo hábil, permitindo que os usuários possam ser influenciados por elas em suas potenciais decisões.

Sobre a compreensibilidade das informações, as compulsórias, inclusive por terem exigências que as tornam bastante complexas, satisfazem apenas de forma parcial esse requisito. Já as voluntárias, uma vez que são de fácil entendimento, se apresentam, em geral, de forma clara e concisa, o que as torna, conforme os parâmetros da CPC (2011), uma informação compreensível.

\section{CONSIDERAÇÕES FINAIS}

Este trabalho teve como objetivo investigar, sob a ótica da Teoria da Legitimidade e dos Custos Políticos quais são e como estão sendo apresentadas as evidenciações contábeis compulsórias e voluntárias que o Governo do Estado de Pernambuco disponibiliza em seu sítio eletrônico.

Considerando que, conforme abordado ao longo do artigo, a redução do custo político e a conquista, manutenção ou recuperação da legitimidade na gestão pública implicam atenção também à evidenciação de informações contábeis. E que não basta divulgar, é preciso divulgar com qualidade, oportunidade e clareza, observando a tempestividade da informação, o seu detalhamento e a relevância necessários. Para isso é preciso que a entidade pública divulgue informações compulsórias e voluntárias, que possibilitem aos usuários ter uma compreensão precisa e completa das atividades desenvolvidas. 
Nota-se com os achados da pesquisa que as evidenciações compulsórias apresentadas pelo Estado de Pernambuco, embora apresente todas as informações previstas em lei, pode-se considerar que não atinge completamente sua legitimidade perante a sociedade, uma vez que não atende de forma total um dos níveis de evidenciação, a justa, bem como uma das características qualitativas, a da compreensibilidade. Também as voluntárias não cumprem totalmente seu papel de legitimação pois, além de serem escassas informações mais analíticas, não atendendo assim de forma total um dos níveis de evidenciação, a completa, também não atende completamente uma das características qualitativas, a da fidedignidade.

De tais achados, pode-se concluir que o Estado de Pernambuco não se sente potencialmente ameaçado em sua legitimidade perante a sociedade. Uma vez não se sentindo potencialmente ameaçado, não considera o aumento do nível e qualidade da evidenciação como elementos essenciais para a manutenção da legitimidade. Assim, depreende-se que o Estado considera o custo político do aumento dos níveis e qualidade das evidenciações frente à perda da legitimidade, uma vez que, conforme afirmam Beuren e Söthe (2009), organizações com custos políticos potencialmente elevados, quando se sentem ameaçadas na sua legitimidade, necessitam ampliar as evidenciações compulsórias e voluntárias, recuperando ou diminuindo a possibilidade de perda da legitimidade.

Recomenda-se para pesquisas futuras, pesquisar os demais estados da região Nordeste, no sentido de verificar se há similaridades com o encontrado para Pernambuco, bem como ampliar a pesquisa para os vinte e sete estados da nação.

\section{REFERÊNCIAS}

AVELINO, B. C.; COLAUTO, R. D. ; CUNHA, J. V. A. Evidenciação, teoria da legitimidade e hipótese dos custos políticos: estudo no governo estadual e municípios de Minas Gerais.. In: $10^{\mathrm{o}}$ Congresso USP de Contabilidade e Controladoria. Anais do $10^{\circ}$ Congresso USP de Contabilidade e Controladoria, São Paulo/SP, 2010.

BEUREN, I. M.; SÖTHE, A. A teoria da legitimidade e o custo político nas evidenciações contábeis dos governos estaduais da região sudeste do Brasil. In: RCO - Revista de Contabilidade e Organizações - FEARP/USP, v. 3, n. 5. 2009.

BISPO, J. S.; CALIJURI, M. S. S.; CASELLA, B.; LIMA, I. S. A importância dos dados contábeis para a relação entre carga tributária, tamanho e setor econômico das empresas brasileiras. In: XIV CONGRESSO BRASILEIRO DE CUSTOS, João Pessoa, 2007. Anais do XIV Congresso Brasileiro de Custos. São Leopoldo: ABCustos, 2007. 
BOFF, M. L. Estratégias de legitimidade organizacional de Lindblom na evidenciação ambiental e social em relatórios da administração de empresas familiares. 2007. Dissertação (Mestrado em Ciências Contábeis) - Programa de PósGraduação em Ciências Contábeis da Universidade Regional de Blumenau, 2007.

BRASIL. Lei no 9.755/1998. Dispõe sobre a criação de "homepage" na "Internet", pelo Tribunal de Contas da União, para divulgação dos dados e informações que especifica, e dá outras providências. Disponível em: <www.planalto.gov.br>. Acesso em 30 nov. 2012.

Lei 4.320/1964. Estatui Normas Gerais de Direito Financeiro para elaboração e controle dos orçamentos e balanços da União, dos Estados, dos Municípios e do Distrito Federal. Disponível em: <http://www.planalto.gov.br/CCIVIL/Leis/L4320.htm>. Acesso em: 30 nov. 2012.

. Lei Complementar no 101/2000. Estabelece normas de finanças públicas voltadas para a responsabilidade na gestão fiscal e dá outras providências. Disponível em: <www.planalto.gov.br>. Acesso em 30 nov. 2012.

. Lei Complementar 131/2009. Estabelece normas de finanças públicas voltadas para a responsabilidade na gestão fiscal. Disponível em: <http://www.planalto.gov.br/ccivil/leis/LCP/Lcp131.htm>. Acesso em: 30 nov. 2012.

COMITÊ DE PRONUNCIAMENTOS CONTÁBEIS. Pronunciamento Conceitual Básico (R1) - Estrutura Conceitual para Elaboração e Divulgação de Relatório Contábil-Financeiro . 2011.

DANTAS, J. A.; ZENDERSKY, H. C.; NIYAMA, J. K. A dualidade entre os benefícios do disclosure e a relutância das organizações em aumentar o grau de evidenciação. In: XXVIII EnANPAD. Anais do XXVIII EnANPAD. Rio de Janeiro: ANPAD, 2004. CDROM.

DIAS FILHO, J.M. Novos delineamentos teóricos em contabilidade. In: RIBEIRO FILHO, J. F.; LOPES, J. E. G.; PEDERNEIRAS, M. (Org.). Estudando Teoria da Contabilidade. 1. Ed. São Paulo: Atlas, 2009.

DOWLING, J. and PFEFFER, J. “Organizational legitimacy: Social values and organizational behavior", Pacific Sociological Review, Vol 18 No 1, pp. 122-36, 1975.

FREY, M. R.; FREY, I. A. Evidenciação social corporativa: estudo de caso longitudinal da empresa Souza Cruz S.A. In: 17 $^{\mathbf{0}}$ Congresso Brasileiro de Contabilidade. Anais do 17ํㅡㄹ Congresso Brasileiro de Contabilidade. Brasília/DF, CFC, 2004. 
GOULART, A. M. C. Evidenciação contábil do risco de mercado por instituições financeiras no Brasil. 2003. Dissertação (Mestrado em Controladoria e Contabilidade) - Curso de Pós-Graduação em Controladoria e Contabilidade, Faculdade de Economia, Administração e Contabilidade da Universidade de São Paulo, 2003.

GRAY, R.; KOUHY, R.; LAVERS, S. “Constructing a research database of social and environmental reporting by UK companies", Accounting, Auditing and Accountability Journal, Vol 8 No 2, pp. 78-101, 1995.

HENDRIKSEN, E. S.; VAN BREDA, M. F. Teoria da Contabilidade. Tradução da americana por Antonio Zoratto Sanvicente. São Paulo: Atlas, 1999.

IUDÍCIBUS, S.; MARTINS, E.; GELBCKE, E. R.; SANTOS, A. Manual de Contabilidade Societária. São Paulo: Atlas, 2010.

MARENS, R., A. WICKS. Getting real stakeholder theory, man- agerial practice, and the general irrelevance of fiduciary duties owes to shareholders. Bus. Ethics Quart. 9(2) 273-292. 1999.

NEU, D.; WARSAME, H.; PEDWELL, K. Managing public impressions: environmental disclosures in annual reports. Accounting, Organizations and Society. V. 23, nº 3. 1998.

O'DONOVAN, G. Corporate environmental reporting: developing a legitimacy theory model. Accounting Association of Australia \& New Zealand - AAANZ Conference, Perth, Western Australia, 7-9 July, 2002.

PATTEN, D. M.; TROMPETER, G. Corporate responses to political costs: an examination of the relation between environmental disclosure and earnings management. Journal of Accounting and Public Policy. v. 22, p. 83-94, 2003.

PLATT NETO, O. A.; CRUZ, F. da; VIEIRA, A. L. Transparência das contas públicas: um enfoque no uso da internet como instrumento de publicidade na UFSC. Revista Contemporânea de Contabilidade, v. 1, n ํㅜㄴ. 2007.

RAUPP, F. M. BEUREN, I. M. Caracterização da pesquisa em Contabilidade. In. BEUREN, Ilse Maria (Org). Como elaborar trabalhos monográficos em contabilidade: teoria e prática. 2. ed. São Paulo: Atlas, 2004. 
SILVA, A. C. R. Metodologia da pesquisa aplicada à contabilidade: orientações de estudos, projetos, relatórios, monografias, dissertações, teses. São Paulo: Atlas, 2003.

SILVA, A. H. C.; SANCOVSCHI, M. Evidenciação social corporativa: estudo de caso da Empresa Petróleo Brasileiro S.A. In: XXX EnANPAD, 2006. Anais do XXX EnANPAD. Rio de Janeiro: ANPAD, 2006. CD-ROM.

SHOCKER, A.D, SETHI, S.P, "An approach to developing societal preferences in developing corporate action strategies", California Management Review, pp.97-105, 1973.

WATTS, R. L.; ZIMMERMAN, J. L. Towards a positive of the determination of accounting standards. The Accounting Review, v. 53, n. 1.1978.

ZIMMERMAN, M. A., \& ZEITZ, G. J. Beyond survival: Achieving new venture growth by building legitimacy. Academy of Management Review, 27, 414-431, 2002. 